\title{
The effect of a child's disability on mother's mental health
}

\author{
K Lambrenos, A M Weindling, R Calam, A D Cox
}

\begin{abstract}
The prevalence of maternal depression was investigated in the mothers of 96 children: 30 premature infants at risk for the development of cerebral palsy; 35 premature infants considered not to be at risk for the development of cerebral palsy; and 31 healthy fullterm infants. There were equally high levels of depression in all three groups of mothers, regardless of birth status, prediction of disability, or presence of actual disability, throughout the first year of the children's lives. Depressed mothers were, however, found to have significantly more psychosocial stress. An early physiotherapy intervention had no effect on the prevalence of depression in mothers whose children were at risk for the development of cerebral palsy.

(Arch Dis Child 1996; 74: 115-120)
\end{abstract}

Keywords: maternal depression, preterm, cerebral palsy, motor disability.

Several studies have indicated that the presence in a family of a child with a physical disability may be detrimental to maternal mental health. ${ }^{1-4}$ If these adverse effects are to be prevented, there needs to be an understanding of the processes involved and a knowledge of when and how a mother's mental health is most likely to be affected. In previous studies, this was often not possible because children with different disabilities were grouped together ${ }^{4}$ or samples included children of widely differing ages. ${ }^{4}$ Often children have been identified from a clinical population but these can differ from children with similar disabilities in the community. Birth and early child rearing can have an adverse effect on maternal mental health even where there is no disability in the child, ${ }^{7}$ so a comparison with healthy children without disability is necessary to understand the specific effects of particular disabilities.

Ultrasound scanning of the neonatal brain has made it possible to detect intracranial lesions which are associated with the development of motor problems. Scans with no abnormalities are usually a reasonably reliable indicator of subsequent normal motor development. ${ }^{89}$ Using this technique infants at risk for the development of cerebral palsy can be identified during the weeks after birth while they are still on a neonatal intensive care unit (NICU). Because parents are routinely informed of the results of such scans and predicted outcomes, it is possible to study prospectively the impact of predicted and actual child disability on the mental health of the mothers. Questions raised include whether maternal depression is precipitated by medical staff communicating their predictions about the later development of the child during the neonatal period; or whether it is only when the parent recognises actual disability in the child at a later date that depression ensues. Perhaps the recognition of delay itself is not sufficient, but rather a growing awareness of how the child might have been as its development falls behind that of peers. The burden of care can be expected to weigh differently according to the child's disability and age and social development. Other factors include the adequacy of support systems, restriction of social life, and the impact of the child's disability on other family relationships. All these can contribute to alterations in maternal mental state.

Preterm birth has also been associated with psychological, social, and environmental stressors, known collectively as conditions of psychosocial deprivation. ${ }^{10-12}$ Such conditions have themselves been associated with higher levels of depression in mothers. ${ }^{13} 14$ The present study provided an opportunity to examine some of these issues during the first year of life, by comparing preterm infants predicted to be at risk for the development of cerebral palsy by neonatal ultrasound scans (half of whom had received an early physiotherapy intervention) with preterm infants not predicted to be at risk for the development of cerebral palsy, and with healthy infants.

This study was designed to test the following hypotheses: (1) that when disability is predicted in preterm infants more mothers will become depressed than when it is not, or in comparison with mothers of healthy term infants; (2) that rates of maternal depression will be higher when their children have a physical disability; (3) that mothers living with high levels of psychosocial adversity will be more depressed than mothers living in less stressful conditions; (4) that predicted or emerging disability combined with psychosocial adversity will result in more mothers becoming depressed; and (5) that the rates of depression in mothers whose children receive early physiotherapy intervention will be lower than for mothers whose children are at risk of impaired neurodevelopment but who are not offered intervention.

\section{Methods}

Our study was embedded within an intervention study designed to assess the impact of early physiotherapy on the motor development 
of preterm infants predicted to develop cerebral palsy on the basis of ultrasound scans. The sample therefore included a subset of mothers involved in that study, with the addition of two contrast groups, namely mothers of a group of preterm infants not predicted to develop cerebral palsy and mothers of a group of healthy term infants.

\section{SELECTION OF THE SAMPLE}

Preterm infants at risk for development of cerebral palsy

All babies admitted to the NICUs of three large urban hospitals were routinely screened by cranial ultrasound. The scans were reviewed by a single observer (AMW) for evidence of porencephalic cysts, cystic periventricular leucomalacia, hydrocephalus, and persistent echodensities.

Before babies with abnormal scans were discharged from the NICU, the scans were shown to the parents and possible neurodevelopmental consequences were explained. The parents were invited to take part in a study that would examine the effects of an early physiotherapy intervention.

At discharge all these infants were considered to be neurologically normal, that is not in a coma, not fitting, and with no overt disturbance of muscle tone, and feeding and responding appropriately for their postmenstrual age. There were no overt signs of physical disability so far as the parents and the medical staff were concerned.

Half of this group of preterm infants with abnormal cranial scans was randomly allocated to a group receiving standard community care, that is, monitoring by their own general practitioners and health visitors as well as attending regular hospital follow up clinics. As and when signs of neurological dysfunction appeared, they were referred to the local child development centre for assessment and treatment by the form of physiotherapy routinely practised there, usually Bobath based. ${ }^{15} 16$

The other half of the infants with abnormal cranial scans was randomly allocated to a group receiving an early physiotherapy intervention. When these babies reached term, they were seen in their own homes by a physiotherapist, at first weekly and then at increasing intervals over the first year of their lives. The physiotherapist used Bobath techniques to advise the mothers on holding and positioning their babies to promote normal posture, with the aim of developing normal muscle tone, inhibiting abnormal postural reactions, and minimising contractures. Later advice was given about handling and playing with the baby to enhance normal movement patterns.

Over a two year period, we recruited all 40 eligible singleton infants and their mothers from the physiotherapy intervention study. Five of these infants died before the first interview at 6 weeks. Of the remaining 35 infants, three died during the course of the study, one family moved and could not be traced, and one family decided to leave the study after 6 months. This left a sample of 30 infants, all
Table 1 Results of cranial ultrascans for 30 babies born prematurely, considered to be at risk for the development of cerebral palsy

\begin{tabular}{ll}
\hline Scan result & $\begin{array}{l}\text { No } \\
\text { of babies }\end{array}$ \\
\hline $\begin{array}{l}\text { Cystic periventricular leucomalacia } \\
\text { Intraventricular haemorrhage and ventricular }\end{array}$ & 14 \\
$\begin{array}{l}\text { dilatation } \\
\text { Intraventricular haemorrhage and parenchymal } \\
\text { involvement }\end{array}$ & 2 \\
Hydrocephalus (arrested and shunted) & 4 \\
Persistent echodensities & 6 \\
\hline
\end{tabular}

with abnormal cranial ultrasound scans (table 1). All had been ventilated during the neonatal period. Of these 30 babies, 16 received early physiotherapy and 14 received standard care with the introduction of physiotherapy when signs of neurological dysfunction were detected. We examined the effect on the mother of predicting disability and of the early introduction of physiotherapy.

\section{Community group of healthy preterm infants}

Each of the 40 infants we recruited from the physiotherapy study was matched for gestational age, birth weight, and sex with the next preterm infant admitted to any of the three NICUs who did not have an abnormal brain scan. All had been mechanically ventilated. Forty healthy preterm infants were thus recruited during the same time period as the at risk group. Of these 40 , two died during the study period, two families moved away and could not be traced, and one family refused to participate after the initial interview. This left 35 infants in the preterm community group.

\section{Community group of term infants}

Thirty one 12 month old children and their mothers were recruited from the community with the help of health visitors from one sector of the city. We examined birth books for the year before the month of recruitment and contacted all eligible babies' mothers. Criteria for recruitment were that there had been no reported complications during the pregnancy or labour. None of the infants had been born prematurely or spent time on an NICU. All were considered by their health visitors to be developing normally. None was suffering from a chronic illness or disability.

\section{Whole sample}

The total sample thus consisted of 96 mothers and their infants - 30 mothers of infants with abnormal brain scans who were predicted to develop cerebral palsy, 35 mothers of healthy preterm infants, and 31 mothers of healthy term infants. Recruitment was based entirely on child characteristics; mothers were expected to vary considerably. The characteristics of mothers and children are described in table 2 . 
Table 2 Characteristics of the 96 mothers and babies at recruitment

\begin{tabular}{|c|c|c|c|}
\hline & $\begin{array}{l}\text { At risk } \\
\text { infants } \\
(n=30)\end{array}$ & $\begin{array}{l}\text { Infants not } \\
\text { at risk } \\
(n=35)\end{array}$ & $\begin{array}{l}\text { Fullterm } \\
\text { infants } \\
(n=31)\end{array}$ \\
\hline \multicolumn{4}{|l|}{ Gestational age (weeks) } \\
\hline Median & & & \\
\hline Range & $23-34$ & $25-34$ & $39-42$ \\
\hline No of males & $14(47 \%)$ & $21(60 \%)$ & $24(70 \%)$ \\
\hline Singleton birth & 30 & 35 & 31 \\
\hline Ventilated neonatally & 30 & 35 & 0 \\
\hline Abnormal ultrasound scans & 30 & 0 & $\dagger$ \\
\hline $\begin{array}{l}\text { Mother's age at birth (years) } \\
\text { Median } \\
\text { Range }\end{array}$ & $\begin{array}{l}26 \\
21-40\end{array}$ & $\begin{array}{l}25 \\
17-35\end{array}$ & $\begin{array}{l}30 \\
20-39\end{array}$ \\
\hline $\begin{array}{l}\text { Social class }^{\mathrm{a}} \\
\text { I } \\
\text { II } \\
\text { III } \\
\text { IV } \\
\text { V }\end{array}$ & $\begin{array}{r}0 \\
4 \\
9 \\
6 \\
11\end{array}$ & $\begin{array}{r}0 \\
5 \\
10 \\
11 \\
9\end{array}$ & $\begin{array}{r}3 \\
8 \\
10 \\
3 \\
7\end{array}$ \\
\hline
\end{tabular}

aSocial class is based on Registrar General's Classification of Occupations (1980) for father's occupation where currently employed, last occupation where currently unemployed, and mother's current or last occupation if single parent mother. †Full term babies did not receive ultrasound scans during neonatal period.

in two ways. First, we administered the malaise inventory, a 24 item self report questionnaire which uses a threshold of 7 to indicate the presence of emotional disorder. ${ }^{17}$ Second, all mothers received a semistructured interview designed to detect depression. Depression was diagnosed using the information gathered and the DSM-III R criteria. ${ }^{18}$ In those cases identified by the malaise inventory, the emotional disorder detected was defined as depression by the results of the semistructured interview.

The mother's relationship with her partner, where one existed, was assessed by the self report dyadic adjustment scale (DAS). ${ }^{19}$

Several psychosocial adversities have been shown to be related to depression in women. ${ }^{131420} \mathrm{~A}$ semistructured interview was constructed in order to collect data on the mother's demographic and social background. (A copy of the interview can be obtained from KL.) Twelve adversities were considered in this study.

(1) Deprived inner city location: mothers were considered to be at risk if they had an inner city postal code.

(2) Housing problems: these were reported by the mothers and could be problems with the fabric of the dwelling or problems with neighbours or the environment.

(3) Unemployed head of household: unemployment lasting at least one month before the interview date.

(4) Mother unemployed: mother not working outside the home. Many were on maternity leave but did not expect to be able to return to work. If this was so they were regarded as unemployed.

(5) Social class: the five classes of the Registrar General's Classification of Occupations ${ }^{21}$ were used for father's occupation if currently employed, or last occupation if currently unemployed, or mother's current or last occupation if she was a single parent.

(6) Four or more children living in the home. (7) No stable relationship: a stable relationship was one where the mother and her hus- band or partner had been together for at least one year before the interview took place.

(8) Poor relationship with partner: this was defined by a score of 96 or less on the DAS. ${ }^{19}$

(9) Problems with mother's family of origin: as perceived by her.

(10) Isolation from social contacts: the mother saw family or friends less than once a week.

(11) Feelings of loneliness: the mother expressed feeling lonely. She may or may not have been isolated from social contacts.

(12) No confidante: that is, no adult to whom she could talk about important issues.

Previous research has shown that while each of these adversities could be coped with alone, there is an additive effect..$^{2022}$ With this in mind we derived a psychosocial adversity scale. The presence of each risk factor scored 1, its absence scored 0 . This gave a possible range of scores from 0 to 12 . We considered a score of 4 or more to indicate psychosocial disadvantage.

\section{INFANT ASSESSMENT}

The motor development of the 65 preterm infants was assessed using the Bayley motor development scale, ${ }^{24}$ which is based on normative maturational developmental data. We paid particular attention to the achievement of major milestones such as sitting independently, weight bearing, and walking. The child was also systematically observed for the presence or absence of obvious visual or motor disability consistent for example with a diagnosis of hemiplegia or blindness.

\section{TIMING OF ASSESSMENTS}

A research psychologist saw each of the preterm mother-infant dyads three times in the first year of the baby's life. Interviews were carried out in the home when the child was 6 weeks, 6 months, and 12 months post term. (Term was considered to be 40 weeks postmenstrual age.) The infant assessment was carried out at 6 months and 12 months post term. The same psychologist saw infants born at term and their mothers when the infants reached their first birthday. All visits were carried out within two weeks of target dates.

DATA ANALYSIS

Data were analysed using the SPSS-PC statistical package: $\chi^{2}$, Fisher's exact test, one or two way analysis of variance (ANOVA), and Student's $t$ test were used as appropriate.

\section{Results}

OVERALL LEVELS OF DEPRESSION

On the basis of the malaise inventory scores, the prevalence of depression among the mothers of the 65 preterm infants remained constant across the first year of the babies' lives: $18(28 \%)$ were depressed at 6 weeks, 19 $(29 \%)$ at 6 months, and $17(26 \%)$ at 12 months. Of the 17 depressed at 12 months, three had not shown depression earlier. The 
Table 3 Association of psychosocial adversity and depression in 96 mothers when their babies were 12 months old

\begin{tabular}{|c|c|c|c|c|c|}
\hline & Depressed & $\begin{array}{l}\text { Not } \\
\text { depressed }\end{array}$ & $\begin{array}{l}\text { Odds } \\
\text { ratio }\end{array}$ & $\begin{array}{l}95 \% \\
\text { Confidence interval }\end{array}$ & $p\left(x^{2}\right)$ \\
\hline $\begin{array}{l}\text { Inner city address } \\
\text { Outer city address }\end{array}$ & $\begin{array}{l}10 \\
15\end{array}$ & $\begin{array}{l}24 \\
47\end{array}$ & $1 \cdot 3$ & 0.5 to 3.3 & NS \\
\hline $\begin{array}{l}\text { Social class III + IV +V } \\
\text { Social class I+II }\end{array}$ & $\begin{array}{r}24 \\
1\end{array}$ & $\begin{array}{l}52 \\
19\end{array}$ & $0 \cdot 1$ & 0.01 to 0.9 & 0.03 \\
\hline $\begin{array}{l}\text { Unemployed head of household } \\
\text { Employed head of household }\end{array}$ & $\begin{array}{l}14 \\
11\end{array}$ & $\begin{array}{l}15 \\
56\end{array}$ & $4 \cdot 8$ & $1 \cdot 8$ to $12 \cdot 6$ & 0.003 \\
\hline $\begin{array}{l}\text { Mother unemployed } \\
\text { Mother employed }\end{array}$ & $\begin{array}{r}19 \\
6\end{array}$ & $\begin{array}{l}39 \\
32\end{array}$ & $2 \cdot 3$ & 0.9 to 7.3 & NS \\
\hline $\begin{array}{l}\text { Poor relationship with partner } \\
\text { Good relationship with partner }\end{array}$ & $\begin{array}{l}13 \\
11\end{array}$ & $\begin{array}{l}12 \\
56\end{array}$ & $5 \cdot 5$ & $2 \cdot 0$ to $15 \cdot 2$ & 0.001 \\
\hline $\begin{array}{l}\text { Problems with housing } \\
\text { No problems }\end{array}$ & $\begin{array}{l}13 \\
12\end{array}$ & $\begin{array}{r}9 \\
62\end{array}$ & $7 \cdot 5$ & $2 \cdot 6$ to $21 \cdot 4$ & 0.0002 \\
\hline $\begin{array}{l}\text { Problems with family of origin } \\
\text { No problems }\end{array}$ & $\begin{array}{l}12 \\
13\end{array}$ & $\begin{array}{l}11 \\
60\end{array}$ & $5 \cdot 0$ & 1.8 to 13.9 & 0.003 \\
\hline $\begin{array}{l}\text { Isolation of mother } \\
\text { Mother not isolated }\end{array}$ & $\begin{array}{r}9 \\
16\end{array}$ & $\begin{array}{r}8 \\
63\end{array}$ & $4 \cdot 4$ & 1.5 to 13.3 & 0.01 \\
\hline $\begin{array}{l}\text { Feelings of loneliness } \\
\text { Not lonely }\end{array}$ & $\begin{array}{r}19 \\
6\end{array}$ & $\begin{array}{l}29 \\
42\end{array}$ & $4 \cdot 6$ & 1.6 to 12.9 & 0.005 \\
\hline $\begin{array}{l}\text { No confidante } \\
\text { Confidante available }\end{array}$ & $\begin{array}{r}9 \\
16\end{array}$ & $\begin{array}{l}11 \\
63\end{array}$ & $3 \cdot 2$ & $1 \cdot 1$ to $9 \cdot 1$ & 0.05 \\
\hline
\end{tabular}

prevalence was similar in the 31 mothers $(n=8$, $26 \%$ ) of healthy term infants when their children were 12 months old.

PREDICTED DISABILITY AND MATERNAL DEPRESSION

At 6 weeks, $10(33 \%)$ of the 30 mothers of infants who had been considered to be at risk for the development of cerebral palsy were depressed, compared to eight of the 35 mothers of healthy preterm infants (23\%). There was no significant difference between the two groups $(t=0.99 ; \mathrm{p}=0.33 ; \mathrm{df}=50)$.

At 6 months, nine $(30 \%)$ of the 30 mothers of infants predicted to develop cerebral palsy were depressed compared to $10(29 \%)$ of the 35 mothers of healthy preterm infants. There was no significant difference between the two groups $(t=0.67 ; \mathrm{p}=0.51 ; \mathrm{df}=56)$.

At 12 months, it was possible to compare the group of mothers of infants predicted to develop cerebral palsy both with the mothers of healthy preterm infants and with the mothers of healthy term infants. Eight (27\%) of the 30 mothers of infants predicted to develop cerebral palsy were depressed compared to nine $(26 \%)$ of the 35 mothers of preterm infants not at risk, and eight (26\%) of the 31 mothers of term infants. A one way ANOVA revealed no significant difference between the three groups $(F=0.03 ; p=0.97$; $\mathrm{df}=2$ ). It appeared that the prediction of disability, which paediatricians based on ultrasound scan evidence, did not result in mothers becoming more depressed.

\section{ACTUAL DISABILITY AND MATERNAL} DEPRESSION

A second hypothesis was that the actual appearance of physical disability would have an effect on depression in the mothers.

At 6 weeks the babies were not assessed for delay or for emerging disability. At 6 months it was difficult to define motor disability. For example, if the motor milestone of sitting inde- pendently is used as an indicator of normal development, ${ }^{21}$ then $74 \%$ of the 65 premature infants were delayed ( 25 of the 30 babies considered to be at risk for motor impairment, and 23 of the 35 of the babies not considered to be at risk). At 12 months, 25 of the 30 infants predicted to develop cerebral palsy showed signs of disability, including failure to use a limb, failure to pull to stand, severe motor incoordination, and lack of vision. These would be consistent with diagnoses of spastic diplegia, hemiplegia, quadriplegia, and blindness. None of the 35 healthy preterm infants or of the 31 healthy term infants displayed any signs of disability.

Of the 25 mothers of infants with disability at 12 months, 7 (28\%) were depressed, compared to nine $(26 \%)$ of the 35 mothers of preterm infants not at risk, and eight (26\%) of the 31 mothers of term infants. A one way ANOVA showed no significant difference between this group and the mothers of healthy preterm and healthy term infants $(F=0.09$; $\mathrm{p}=0.916 ; \mathrm{df}=2)$. Hence the appearance of disability was not associated with level of depression in the mothers.

\section{PSYCHOSOCIAL ADVERSITY AND MATERNAL} DEPRESSION

Information was gathered on the 12 adversities described above. Initially we examined the relation between the 12 adversities and the level of depression for the total sample of 96 mothers of 12 month old infants. There were too few mothers without a stable relationship to test for significance. Similarly there were very few mothers with four or more children. $\chi^{2}$ Tests were carried out for each of the remaining 10 adversities (table 3). An inner city address and whether or not the mother was unemployed were not significantly related to depression. The proportion of mothers with depression was significantly higher in the presence of each of the remaining eight adversities.

When the 65 mothers of 12 month old babies who had been born prematurely were examined alone, similar patterns emerged but with two differences (table 4 ). The lack of a confidante ceased to be significant, and social class also failed to reach significance, though this had only just reached significance in the larger group so the change is likely to be an artefact of sample size.

The importance of each of the psychosocial adversities changed over the course of the year when data were collected (table 5). At 6 weeks, there were no significant differences in the numbers of mothers who were depressed in the presence of each adversity with one exception: the presence of problems with housing. At 6 months, the numbers of mothers who were depressed were significantly different where there was unemployment, problems with the mother's family of origin, where the mother was isolated, feeling lonely and without a confidante, and having problems with housing. These adversities continued to be significant at 12 months. A poor relationship with a partner only became significant as an adversity 
Table 4 Association of psychosocial adversity and depression in 65 mothers when their preterm babies were 12 months old (age corrected for prematurity)

\begin{tabular}{|c|c|c|c|c|c|}
\hline & Depressed & $\begin{array}{l}\text { Not } \\
\text { depressed }\end{array}$ & $\begin{array}{l}\text { Odds } \\
\text { ratio }\end{array}$ & $\begin{array}{l}95 \% \\
\text { Confidence interval }\end{array}$ & $p\left(x^{2}\right)$ \\
\hline $\begin{array}{l}\text { Inner city address } \\
\text { Outer city address }\end{array}$ & $\begin{array}{r}5 \\
12\end{array}$ & $\begin{array}{l}13 \\
35\end{array}$ & $1 \cdot 1$ & 0.3 to 3.8 & NS \\
\hline $\begin{array}{l}\text { Social class III }+\mathrm{IV}+\mathrm{V} \\
\text { Social class } \mathrm{I}+\mathrm{II}\end{array}$ & $\begin{array}{r}16 \\
1\end{array}$ & $\begin{array}{r}40 \\
8\end{array}$ & 0.3 & 0.04 to $2 \cdot 7$ & NS \\
\hline $\begin{array}{l}\text { Unemployed head of household } \\
\text { Employed head of household }\end{array}$ & $\begin{array}{l}9 \\
8\end{array}$ & $\begin{array}{l}11 \\
37\end{array}$ & $3 \cdot 8$ & $1 \cdot 2$ to $12 \cdot 2$ & 0.05 \\
\hline $\begin{array}{l}\text { Mother unemployed } \\
\text { Mother employed }\end{array}$ & $\begin{array}{r}13 \\
4\end{array}$ & $\begin{array}{l}31 \\
17\end{array}$ & 1.8 & 0.5 to 6.3 & NS \\
\hline $\begin{array}{l}\text { Poor relationship with partner } \\
\text { Good relationship with partner }\end{array}$ & $\begin{array}{r}10 \\
7\end{array}$ & $\begin{array}{l}10 \\
38\end{array}$ & $5 \cdot 4$ & 1.7 to 17.9 & 0.009 \\
\hline $\begin{array}{l}\text { Problems with housing } \\
\text { No problems }\end{array}$ & $\begin{array}{r}11 \\
6\end{array}$ & $\begin{array}{r}7 \\
41\end{array}$ & $10 \cdot 7$ & 3.0 to 38.5 & 0.0003 \\
\hline $\begin{array}{l}\text { Problems with family of origin } \\
\text { No problems }\end{array}$ & $\begin{array}{r}10 \\
7\end{array}$ & $\begin{array}{r}9 \\
39\end{array}$ & $6 \cdot 2$ & 1.9 to 20.7 & 0.005 \\
\hline $\begin{array}{l}\text { Isolation of mother } \\
\text { Mother not isolated }\end{array}$ & $\begin{array}{r}5 \\
12\end{array}$ & $\begin{array}{r}3 \\
45\end{array}$ & $6 \cdot 3$ & 1.3 to 20.9 & 0.04 \\
\hline $\begin{array}{l}\text { Feelings of loneliness } \\
\text { Not lonely }\end{array}$ & $\begin{array}{r}14 \\
3\end{array}$ & $\begin{array}{l}22 \\
26\end{array}$ & $5 \cdot 5$ & 1.4 to $21 \cdot 7$ & 0.02 \\
\hline $\begin{array}{l}\text { No confidante } \\
\text { Confidante available }\end{array}$ & $\begin{array}{r}6 \\
11\end{array}$ & $\begin{array}{r}8 \\
40\end{array}$ & $2 \cdot 7$ & 0.8 to 9.5 & NS \\
\hline
\end{tabular}

associated with depression when the children were 12 months old (table 5).

When scores on the psychosocial scale were examined, levels of psychosocial disadvantage (that is, a score of 4 or more) were high across the whole sample of mothers. At 12 months, 44 of the 96 mothers could be classed as disadvantaged. If levels of psychosocial adversity as measured by the adversity scale were high, then the mothers were more likely to be depressed $\left(\chi^{2}=19 \cdot 82, \mathrm{p}=<0 \cdot 001\right)$.

\section{INTERACTION OF PSYCHOSOCIAL ADVERSITY AND DISABILITY}

Since the prediction of presence of disability in the child could have caused added stress to the mothers and might have been associated with depression, the data were analysed to test if there was an interactive effect of psychosocial adversity and predicted disability on depression. No effect for the interaction could be found either at 6 weeks $(F=0.01$, $\mathrm{p}=0.93, \mathrm{df}=1)$, or at 6 months $(\mathrm{F}=0.89$, $\mathrm{p}=0.35, \mathrm{df}=1$ ) for the 65 mothers of preterm infants, or at 12 months for the whole sample of 96 mothers $(F=0.59, p=0.56$, $\mathrm{df}=2$ ).

Table 5 Psychosocial variables significantly associated with depression in mothers of 65 babies born prematurely using $\chi^{2}$ analysis

\begin{tabular}{|c|c|c|c|}
\hline \multirow[b]{2}{*}{ Adversity } & \multicolumn{3}{|c|}{ Age of baby at time of assessment ${ }^{1}$} \\
\hline & 6 Weeks & 6 Months & 12 Months \\
\hline $\begin{array}{l}\text { Inner city address } \\
\text { Social class III, IV, and V } \\
\text { Unemployed head of household } \\
\text { Mother unemployed } \\
\text { Poor relationship with partner } \\
\text { Problems with housing } \\
\text { Problems with family of origin } \\
\text { Isolation of mother } \\
\text { Feelings of loneliness } \\
\text { No confidante available }\end{array}$ & $\begin{array}{l}\text { NS } \\
\text { NS } \\
\text { NS } \\
\text { NS } \\
\text { NS } \\
\sim \\
\sim\end{array}$ & $\begin{array}{l}\text { NS } \\
\text { NS } \\
\star \\
\text { NS } \\
\ddagger \\
\neq \\
\neq \\
\ddagger \\
\ddagger \\
\ddagger\end{array}$ & $\begin{array}{l}\text { NS } \\
\text { NS } \\
\text { NS } \\
\dagger \\
\ddagger \\
\ddagger \\
\ddagger \\
\ddagger \\
\ddagger\end{array}$ \\
\hline $\begin{array}{l}\text { No stable relationship } \\
4+\text { children living at home }\end{array}$ & & & \\
\hline
\end{tabular}

${ }^{1}$ Ages corrected for prematurity.

${ }^{2}$ Frequencies too small to test reliably.

$\sim$ Data not collected at this age.

Significance levels: $\neq \mathrm{p}<0.001 ; \mathrm{tp}<0.01 ;{ }^{\star} \mathrm{p}<0.05$.
A further two way ANOVA was carried out to test if there was an interactive effect for psychosocial adversity and actual disability on depression for the whole sample of 96 mothers at 12 months; we found no interactive effect $(\mathrm{F}=0.59, \mathrm{p}=0.56, \mathrm{df}=2)$.

\section{IMPACT OF AN EARLY PHYSIOTHERAPY} INTERVENTION

Of the 16 mothers of preterm infants where an early physiotherapy intervention was planned, seven $(44 \%)$ were depressed at 6 weeks, six $(38 \%)$ at 6 months, and five $(31 \%)$ at 12 months. For the 14 mothers where standard care was planned, the numbers were three $(21 \%)$, three $(21 \%)$, and three $(21 \%)$.

We analysed mothers' malaise inventory scores for the two groups using the Student's $t$ test. There was no significant difference between the two groups at 6 weeks, 6 months, or 12 months (table 6 ).

\section{Discussion}

Over the first year of the infants' lives neither the prediction of disability nor the appearance of actual disability increased the numbers of mothers who were depressed. What was evident from this study was the pervasive influence of psychosocial adversity on the mothers' mental health. High levels of psychosocial disadvantage were associated with depression in all groups and at all times of assessment.

The combination of a deprived psychosocial environment and the presence of a child predicted to develop disability did not increase the mothers' vulnerability for depression. We found no effect of actual appearance of disability by one year either. It is possible that the levels of psychosocial adversity with which these mothers were coping were already so high that the effect of the added stress of a child with a potential or an actual disability could not be detected.

We offer some tentative suggestions about the process by which depression might be sustained in the group of 65 mothers of preterm babies. At 6 weeks the experience of preterm birth and bringing the child home to adverse housing conditions were associated with depression. By 6 months, depression was found in mothers experiencing a lack of support from family and friends and lack of money from unemployment. At 12 months, lack of paternal support became a salient factor. This suggests that the mothers' needs for support changed as

Table 6 Results of analysis of malaise inventory scores for 30 mothers of preterm children with abnormal brain scans

\begin{tabular}{llllll}
\hline & $N o$ & Mean & $S D$ & $\mathrm{t}$ & $p$ \\
\hline 6 Weeks & 16 & 7.25 & 6.74 & & \\
$\quad \begin{array}{l}\text { Early intervention } \\
\text { Standard care }\end{array}$ & 14 & 4.00 & 2.54 & 1.79 & 0.09 \\
$\begin{array}{l}\text { Months } \\
\text { Early intervention }\end{array}$ & 16 & 6.12 & 6.25 & & \\
$\quad \begin{array}{l}\text { Standard care } \\
\text { Months }\end{array}$ & 14 & 4.86 & 3.61 & 0.69 & 0.50 \\
$\quad \begin{array}{l}\text { Early intervention } \\
\text { Standard care }\end{array}$ & 16 & 5.12 & 5.68 & & \\
& 14 & 4.21 & 4.64 & 0.48 & 0.63
\end{tabular}


their infants grew. However, this was probably not related to the burden of care, because the prevalence of depression in the mothers of infants at risk for the development of cerebral palsy was no different from that in mothers of healthy preterms or healthy term infants. We hypothesise that the burden of care is not so different for mothers of children with disabilities during the first year of life. However, there are some indications that the adequacy of support and, as time progresses, the interparental relationship are influential.

We had hypothesised that early intervention would be supportive for mothers of children with abnormal brain scans and would decrease rates of depression. In fact the proportion of mothers who were depressed was higher in the group receiving early intervention than in the group receiving standard care. It may have been that the weekly presence of the physiotherapist drew attention to the condition of the child, whereas mothers in the standard care group were not reminded of the potential disability in their child, so did not become depressed. Although the rate of depression of mothers in the early intervention group remained higher than that for the group of mothers of preterm children receiving standard care over the first year of life, the difference was not significant and the rate declined with time. Mothers in the standard care group received increasing levels of professional support over time, and their rates of depression did not change.

On the basis of the data presented here we consider that the timing of physiotherapy intervention needs to be sensitively related to the appearance of disability in the child. Although these findings suggest that mothers may accommodate better to physiotherapy if it starts at the point when disability becomes evident, there could be other important benefits of early intervention for the child's development or for the relationship between mother and child. Results from the much larger physiotherapy study show that there could be some benefit to motor development at 12 months for children receiving early physiotherapy intervention (to be published).
This study was financed by Mersey Regional Health Authority, Research Scheme No 583 .

1 McMichael J K. Handicap: a study of physically handicapped children and their families. London: Longmans, 1971.

2 Butler N, Gill R, Pomeroy D, Fartrell J. Handicapped children - their homes and lifestyles. Bristol: Department of Child Health, 1978.

3 Burden RL. Measuring the effects of stress on the mothers of handicapped infants: must depression always follow? Child Care Health Dev 1980; 6: 111-25.

4 Frey KS, Greenberg MT, Fewell RR. Stress and coping among parents of handicapped children: a multidimen sional approach. Am f Ment Retard 1989; 94: 240-9.

5 Waisbren SE. Parents' reactions after the birth of a developmentally disabled child. Am $\mathcal{f}$ Ment Defic 1980; 84: 345-51.

6 Sloper P, Turner S. Risk and resistance factors in the adaption of parents of children with severe physical disability. $\mathcal{f}$ Child Psychol Psychiatry 1994; 34: 167-88.

7 Puckering C. Maternal depression. $\mathcal{f}$ Child Psychol Psychiatry 1989; 30: 807-17

8 Graham M, Levene MI, Trounce JQ, Rutter N. Prediction of cerebral palsy in very low birthweight infants: Prospective ultrasound study. Lancet 1987; i: 593-6.

9 Stewart A, Hope PL, Hamilton P, et al. Prediction in very preterm infants of satisfactory neurodevelopmental progress at 12 months. Dev Med Child Neurol 1988; 29: progress

10 Kramer MS. Determinants of low birth weight: Methodological assessments and meta-analysis. Bull WHO 1987; 65: 663-737.

11 Binsacca DB, Ellis J, Martin DG, Petitti DB. Factors associated with low birthweight in an inner city population: The role of financial problems. Am $\mathcal{F}$ Public Health 1987; 77: 505-6.

12 Ericson A, Eriksson $M$, Kallen B, Zetterstrom R. Socioeconomic variables and pregnancy outcome. Acto Paediatr Scand 1989; 360: 48-55

13 Brown GW, Harris T. Social origins of depression. London: Tavistock Publications, 1978.

14 Stein A, Cooper PJ, Campbell EA, Day A, Altham PME. Social adversity and perinatal complications: their Social adversity and perinatal complications: their
relation to postnatal depression. $B M \mathcal{F} 1989$; 298: relation

15 Bobath B. Treatment principles and planning in cerebral palsy. Physiotherapy 1963; 49: 122-6.

16 Bobath B. The very early treatment of cerebral palsy. Dev Med Child Neurol 1967; 9: 373-90

17 Rutter M, Tizard J, Whitmore K, eds. Education, health and behaviour. London: Longmans, 1970.

18 American Psychiatric Association. Diagnostic and statistical manual of mental disorders. 3rd Ed. Washington DC: American Psychiatric Association, 1980.

19 Spanier GB. Measuring dyadic adjustment: new scales for assessing the quality of marriage and similar dyads. I Marriage Family 1979; 38: 15-28

20 Fendrich M, Warner V, Weissman MM. Family risk factors, parental depression and psychopathology in offfactors, parental depression and psych
spring. Dev Psychol 1990; 26: 40-50

21 Registrar General's classification of occupations. London: HMSO, 1980.

22 Rutter M. Early sources of security and competence. In: Bruner JS, Garton A, eds. Human growth and development. Bruner JS, Garton A, eds. Human growt
Oxford: Oxford University Press, 1978.

23 Rutter M, Quinton D. Psychiatric disorder - ecological factors and concepts of causation. In: McGurk $\mathrm{H}$, ed. Ecological factors in human development. Amsterdam: New Holland, 1977.

24 Bayley N. Bayley scales of infant development. New York: Psychological Corporation, 1969. 